\title{
The Language Faculty - Mind or Brain?
}

TORBEN THRANE

\author{
Aarhus University, School of Business, Denmark
}

\begin{abstract}
Artiklens sigte er at underkaste Chomskys nyskabende nominale sammensætning - "the mind/brain" - en nøjere undersøgelse. Hovedargumentet er at den skaber en glidebane, således at det der burde være en funktionel diskussion - hvad er det hjernen gør når den behandler sprog? - i stedet bliver en systemdiskussion hvad er den interne struktur af den menneskelige sprogevne? Argumentet søges ført igennem under streng iagttagelse af de kognitive videnskabers opfattelse af information og repræsentation, specielt som forstået af den amerikanske filosof Frederick I. Dretske.
\end{abstract}

\section{INTRODUCTION}

Cartesian dualism is dead, but the central problems it was supposed to solve persist: What kinds of substances exist? Are bodily things (only) physical, mental 'things' (only) metaphysical? How is the mental related to the physical? Although "we are all materialists now", such questions still need answers, and they still need answers from within realist and naturalist bounds to count as scientific.

Linguistics is a discipline that may be expected to contribute with answers to such questions. No one in their right mind would deny that our ability to acquire and use human language is lodged between our ears - inside our heads. That is, in our brains and/or minds. In some quarters it has been customary for the past 50 odd years or so to regard this ability as a distinct and dedicated cognitive ability on a par with our abilities to see (vision) or to keep our balance (equilibrioception), and to refer to it as the Human Language Faculty (HLF). This has been the axiomatic starting point for the development of main stream generative linguistics as founded by Chomsky in 1955 in what I shall refer to as 'Chomsky's programme'.

Christensen, Ken Ramshøj (ed.), Cognition/Kognition, Århus: Statsbiblioteket Tidsskrift for Sprogforskning, årgang 7, 2009

Artikel nr. 5, Thrane, Torben, 42 pp.

http://ojs.statsbiblioteket.dk/index.php/tfs/index 
In that programme, HLF is assumed to be neutral with respect to production and reception of utterances, on the grounds that it would be 'unnatural' to assume that we were endowed with two radically distinct faculties, one for production and one for reception and understanding. This may appear to be a reasonable view, but the fact remains that production and reception are radically distinct processes. It is therefore only a reasonable view at a level of abstraction at which HLF is regarded as an insulated system, closed off relative to other cognitive systems, a system that can be shown to be relevantly engaged in both production and reception, but which at the same time can be shown to remain immune from those factors that make production and reception different processes, a sort of "brain in a vat".

This view is a priori. Rejecting it, or rather suspending judgement on it to be confirmed or falsified by empirical evidence, this paper will discuss some of the key issues in Chomsky's programme with a view to determining whether it is equipped to answer what I take to be a more legitimate a priori question: How can we explain the manifest human ability to understand linguistic utterances as vehicles for the expression of thoughts and ideas?

The next section will present a number of "leading ideas" underlying Chomsky's programme. The following main sections will then deal with these under the following rubrics: Representational Theories of Mind, Representational Systems, Representational Architectures, and The Language Faculty in Brain Studies. A Conclusion will sum up the main argument.

\section{Three LeVELS OF CHOMSKYAN LINGUISTICS}

Chomsky has coined the nominal compound "mind/brain" as his contribution to the solution of the dualist dilemma. He has consistently argued that linguistics is a subbranch of biology, and that the study of HLF should be pursued on methodologically naturalist grounds - that is, that we stand the best chance of understanding the world, including such immaterial things as consciousness and intentionality, by pursuing them by the methods of the natural sciences. He has also consistently maintained that the programme he has been endorsing from the mid-1950's until today is the same project, even in the face of a number of obvious changes in its technical details. 
Chomsky often launches major revisions of those details by pointing to a significant distinction, or asking a small number of questions, pursuit of which will lead to corrections, big or small, of the course as charted until then. Government and Binding (GB) (Chomsky 1981) was launched from the distinction made in (I):

(I) 1. What are the "leading ideas" of linguistics (as propounded in work culminating in Chomsky 1978)?

2. How are these "leading ideas" best executed?

$G B$, roughly, was seen as a revision in execution, rather than of ideas. Chomsky (1986), in the first major break with the leading idea of 'rule following', asked the famous three questions in (II):

(II) 1. What constitutes knowledge of a language?

2. How is knowledge of language acquired?

3. How is knowledge of language put to use?

The interesting one, according to Chomsky, was (II, 1), and it can only be answered via answers to (II, 2). The last question, (II, 3) has never been at the forefront of Chomsky's own research (though cf. Chomsky 2000), generally on the grounds that it is too "diffuse" to merit serious attention in empirical research.

The Minimalist Program (MP) (Chomsky 1995b) corrected the course by posing the two questions in (III). The first of these had subquestions, one asking about the place of the language faculty among other cognitive systems, the second about 'conceptual naturalness'.

(III) 1. What are the general conditions that the human language faculty should be expected to satisfy?

2. To what extent is the language faculty determined by these conditions, without special structures that lie beyond them?

MP may be seen as a sweeping blow with Occam's razor in that it seeks to dispense with principles and conditions that cannot be motivated by "virtual conceptual necessity", a phrase that has engendered not a little controversy 
(Postal 2003). It has also turned out to be a somewhat empty blow in that MP to a large extent still avails itself of much of the technical apparatus across which the principles and conditions it seeks to eliminate were first defined. I give an example below.

Each set of distinctions and questions has triggered worldwide research programmes in a number of disciplines. The latest indication of a slight change of course (Chomsky 2004: 104-105) is the single question in (IV, 4) "asking not only what the properties of language are, but why they are that way", after first specifying the properties of attained language states (I-languages) as the result of the three factors in (IV, 1-3). " $\mathrm{S}_{0}$ " is the initial state of the language faculty, "PLD" is the primary linguistic data to which children are exposed and which thus triggers the language faculty to develop into individually attained states.

(IV) 1. Individual experience (PLD), which selects among the options allowed by $\mathrm{S}_{0}$.

2. $\mathrm{S}_{0}$ itself, a product of evolution.

3. General properties of organic systems.

4. Why is the language faculty the way it is?

This last question goes "beyond explanatory adequacy". At least it goes beyond the stage at which it is still legitimate to ask what the language faculty is like. It presumes that we now know this. It is thus pointing towards new directions, revitalizing biolinguistic and neurolinguistic programmes.

These four changes home in on three general 'levels' within the overall theory, which might be formulated as a further triplet of questions:

(2) a. From (I): What are the technical details needed to formalize the "leading ideas"?

b. From (II): How are the "leading ideas" expressed as properties of the mind/brain?

c. From (III, IV): What kind of constraints regulate the expression of the "leading ideas" as properties of the mind/brain?

The "leading ideas" are taken as constants, except for the shift from "rule following' to statements of principles and conditions. This particular change, I 
think, was enforced by a general concern for 'psychological reality'. No lasting success had come from psycholinguistic experiments in the 1960's and 1970's to support theses about processing time as a relevant parameter in the account of transformations, for example (Townsend \& Bever 2001: 26ff), and the whole idea of 'trees in the head', to say the least, seemed counterintuitive. Modern methods of brain scanning put more stock on amounts and areas of neuronal activation.

From among a longer list of "leading ideas", I shall be concerned here with the following four, with special focus on the italicized parts:

(3) a. The human language faculty is an innate, species-specific, autonomous component of the "mind/brain".

b. Its central component is a computational mechanism, an I-language, which generates representations on the basis of information.

c. Its function is to pair representations of sound with representations of meaning.

d. Representations are states of the "mind/brain" at a subconscious (or perhaps 'infraconscious') level of awareness.

As is evident from (2), the development of the overall theory has progressed from investigation of technical questions of language structure, through considerations of how these technical matters may be expressed in human cognition, to questions of how to constrain such expressions in biological terms. Answers to questions of a technical nature have been taken to supply, or sustain, answers to question $(2, b)$. The result has been an impressive accumulation of detailed knowledge of the structural properties of particular languages, on the understanding that many of these are predicted as specific instantiations of properties of universal grammar (UG), the initial state, $S_{0}$, of (IV, 2). With the advent of $(2, c)$, many of these results have been revised, even - at least rhetorically - rejected. To claim that "government", for example, no longer plays a role as a structural principle does not carry much weight when the machinery over which government was first defined as a structurally significant principle, is retained in the form of a version of X-bar theory (Chomsky 1995b: 173). Of course, as also stated, (head) government is still there, as a consequence of the properties of the notational scheme used to represent language structure, but it needs to be reformulated in terms of "local relations". What the claim amounts 
to, then, is a prediction that government plays no role in the cognitive or biological expressions of the grammar.

I will not be talking much about the technical aspects $(2$, a). They have undergone so many changes over time that it is difficult to pin down what 'Chomsky's programme' is in technical terms. Culicover and Jackendoff (2005: Chs. 2-3) make a bold attempt to keep track of it through time. Nor would it be reasonable to regard these various technical versions as just Chomsky's, for many of the details are due to proposals made by other investigators working within the mainstream. I regard these various versions as so many 'surface structures', different material realizations of the same "leading ideas", which under this view may be regarded as providing an 'underlying structure' of assumptions. These, Chomsky often says, haven't changed since 1955. It is this structure of assumptions converging on $(2, \mathrm{~b}, \mathrm{c})$ I have in mind when I talk about 'Chomsky's programme', and it is the role they play in the pursuit of his goal of explaining the human language faculty that I query. This leads to the somewhat paradoxical situation of defending Chomsky against attacks on generativism on the one hand, and criticizing him for the way he pursues it on the other.

My aim is emphatically not to reject Chomsky's goal or generativism in general. On the contrary. It is an important goal to pursue, and generativism, it seems to me, is the only way to pursue it. But I happen to believe that it cannot be reached by revising or changing the technical machinery dealt with under question $(2, a)$, or by adding to what I above called the 'surface structures' of the theory. My main criticism is directed at the conclusions drawn from technical matters to the nature of the underlying structure of assumptions and, in particular, the bounds of idealization that Chomsky sets up, in my view too narrowly to further his cause, and the investigative consequences he draws within these bounds with respect to the notions of information and representation. The main inspiration for this project has been the writings of Frederick I. Dretske, an American philosopher whose work in epistemology is firmly grounded precisely in these two notions. 


\section{REPRESENTATIONAL THEORIES OF MIND}

How the brain is composed and how it works is reasonably well understood and I won't go into that here (see e.g. Feldman 2008: Part II). The mind is rather more mysterious.

\subsection{Mind Models}

Relevant discussion has been conducted from within a body of ideas known as "The Computational Theory of Mind" (CTM), whose central theses are that the mind is a computational device, embodied in the neuronal network of the brain, which generates symbolic representations in the form of syntactic objects, and that thinking is a matter of formally manipulating these objects.

CTM presupposes another set of ideas known as "The Representational Theory of Mind" (RTM), which holds that intentional states like believing, hoping, and wishing are in fact relations between someone who believes, hopes, or wishes something and mental representations with a particular semantic content characterizing those states. However, this has not been so much of an issue in generative linguistics proper as in the psycholinguistic programmes inspired by it, like, most famously, Jerry Fodor's (1975) theory of a Language of Thought. In generative linguistics proper, the function of HLF is just to generate syntactic objects through a sequence of processes comprehensively known as a derivation. It is, nevertheless, an important point, and I return to it in more detail below.

Taking both CTM and RTM into consideration, HLF as a mental phenomenon is supposed to be embodied in the brain as a computational device, and its function is to generate mental representations which can be semantically interpreted on the basis of informational input through derivation.

\subsection{Organization of Computational Models}

As a computational device, HLF is assumed to be amenable to the three levels of description and explanation that David Marr (1982: 25) formulated for such systems:

- A level of computational theory, which specifies what the goal of the computation is, why it is appropriate, and what the logic of the strategy is by which it can be carried out. 
- A level of representation and algorithms, which specifies how this computation can be implemented; in particular, what the representation for the input and output is, and what the algorithm for the transformation is.

- A level of physical implementation, which specifies how the representation and algorithm can be implemented.

I have argued (Thrane 1992a, b) that a fourth level is needed when the information that the system operates on stems from linguistic signals - cf. also Peacocke (1986), who dubs it "the 11/2-level":

- A level of information, which specifies the nature of the information required by the computation, and how the required information is made available to it.

\subsection{Meaning and Information as Semantic and Informational Content}

Once the issue of information is brought to the forefront, it soon becomes clear that discrimination must be made between information understood as a physical epiphenomenon, and information understood in semantic terms, as roughly equivalent to meaning, even though this distinction is not always made: "meaning is information (more or less)" (Fodor 1998: 12 - cf. Floridi 2005 for thorough discussion of this large issue).

This lack of discrimination is due to apparently perceived problems surrounding the nature of the representations that HLF is supposed to generate. Although the verb 'represent' is truly transitive, the derived nominal need not be. Something may be a representation pure and simple, not a representation of something, or to somebody. One definition of 'representation' states:
On this [computational] view [of cognition], a representation is any internal state that mediates or plays a mediating role between a system's inputs and outputs in virtue of that state's semantic content. We define semantic content in terms of information causally responsible for the state, and in terms of the use to which such information is put. Hence, any state that mediates between the input to an agent and the actions performed by the agent is a representation (Dietrich \& Markman 2003: 97).

This definition highlights two troublesome points about representation - the claim, first, that representations (mental states) have semantic content, and the 
claim, secondly, that whatever semantic content a representation has is causally responsible for behavioural output.

In defence of the first claim, Dietrich \& Markman appeal to Dretske, who carefully distinguishes between the informational and the semantic content of signals, but it will take me too far afield to unravel this distinction in detail here (cf. Dretske 1981: Chs. 3 and 7 for discussion). For my purpose it suffices to say that the informational content of a signal is the total amount of information it carries about a given state of affairs, whereas the semantic content of a signal is that piece of information which the receiver extracts as the most specific piece of information carried by it. To give a brief example, one observer of a particular object, $x$, may extract the information from a visual signal that $x$ is a car; whereas another observer may extract - from the 'same' signal - the information that $x$ is a Lamborghini Diablo SE 30. The information that $x$ is a car is said to be nested in the information that $x$ is a Lamborghini Diablo SE 30. Hence, the semantic content of a signal is whatever information the receiver extracts as its outermost informational shell.

The second point concerns the intentionality of states at Marr's three levels of explanation listed above. Lurking behind it is the ghost of the second, necessary, argument of the verb 'represent', which - or so the argument apparently goes must at least haunt the derived nominal. A representation must be about something to be a representation, and it must be what the representation is about - its reputed semantic content - that must be the cause of behavioural output.

\subsection{The Nature of Representation}

In an exposition of Marr's theory of vision, Egan (1995 - further developed in Egan 2003) provides a persuasive explanation why this need not be the case. If a representation is a mapping between structures A and B, the formal means of creating $B$ at each level of representation are entirely independent of the formal properties of A. Not until a function is appointed by which elements of B are interpreted as related to elements of A does intentionality arise, and it does so under the presumption that the representation is generated under normal conditions imposed by natural constraints. Now, this may still sound as if B is 'about' A - having been caused by it, or at least being causally dependent on it. 
Indeed. But the point is that B does not 'know' this. It is not $B$ that is intentional. Only an external - external to B - interpreter knows it. An external interpreter assigns intentionality to $\mathrm{B}$. The system, in generating B, does whatever it is its job to do, even in circumstances where it would not be reasonable to do so, and even when doing so leads to misrepresentation. To exemplify, Egan (1995: 196, note 17) gives the following scenario; Dretske (1986) is a lengthier discussion of the same point.

\begin{abstract}
Suppose that, as part of a military training exercise, Bill, a normal human with a Marrian visual system, is placed in a room where the continuity constraint, which holds that disparity varies smoothly because matter is cohesive, is not satisfied. Bill's visual system normally computes depth from disparity information. However, in these circumstances, where spikes of matter project in all directions, Bill (or, more specifically, the stereopsis module of Bill's visual system) will compute the same formally characterized function as he normally does, but he will misrepresent some other property (not a property for which we have a convenient name) as depth. In general, where the constraints that normally enable an organism to compute a cognitive function are not satisfied, it will fail to represent its environment.
\end{abstract}

The system works impeccably, the representation it generates is the representation it is supposed to generate, and the interpretation of it (by Bill) is the one he usually performs - only in this case, the information on the basis of which the computation was made, does not arise under normal conditions imposed by natural constraints. So, the signal misrepresents 'something' as depth.

Even though the technical sense in which the cognitive sciences understand representation is simply that it is a state of an information-processing system, without prejudice of either correspondence or interpretation, the system must be receptive to different types of information - something it will 'recognize' as relevant information - depending on the representational state it is in at that particular step in the overall process. Clearly, this information must be organized in a way which makes it explicit to the processor, and conditions, furthermore, have to be 'normal'. Our auditory system works poorly under water.

In a discussion of these matters, Chomsky (1995a: 52) comments on a number of points made by Shimon Ullman, David Marr's colleague and collaborator. 


\begin{abstract}
His studies of determination of structure from motion used tachistoscopic presentations that caused the subject to see a rotating cube, though there was no such thing in the environment; "see", here, is used in its normal sense, not as an achievement verb. If Ullman could have stimulated the retina directly, he would have done that; or the optic nerve. The investigation, Ullman writes, "concerns the nature of the internal representations used by the visual and the processes by which they are derived" [reference to S. Ullman, The Interpretation of Visual Motion, Cambridge, Mass.: MIT Press, 1979, p. 3]. The account is completely internalist.
\end{abstract}

Quite so, but there is equivocation here. Some form of excitation (of retina, or optic nerve) is necessary for further representations to be generated and for relevant processes to run. It is no doubt true to say that the representations generated by tachistoscopic presentations in this way are not 'about' cubes - but it was nevertheless representations of 'nothing' as cubes. To the subjects in the experiment, they were cubes, just as tinnitus 'sound' is sound. What the subjects responded to was the semantic content of the representations - that they were 'cubes' - not the informational content of the representations generated by the more "proximal" patterns of activation on the retina, in Dretske's (1981: 183) terms.

The necessary excitatory agent in this account is information, in particular information carried by linguistic utterances. By Chomsky's token, this does not mean that whatever representations such information causes, necessarily are 'about' anything in externalist terms. Even though this is true, however, such representations must be as if something, just like Ullman's cubes. Even though linguistic utterances may be about cubes (or mermaids, or whatever) without there being any cubes (mermaids) for them to externally 'represent', the information they carry must nevertheless internally represent 'nothing' as cubes (mermaids) for the utterance to be about cubes (mermaids).

\title{
3.5. The Generation vs. Application of Representations
}

Egan (2003: 97), though in essential agreement with Chomsky, frames the same issue in a discussion of Marr's computational levels:

From the fact that a computational theory is an account of the processes by which certain internal structures are derived, and from the fact that representational [i.e., semantic, in Dretske's terms - TT] content plays no 
individuative role within a computational theory, it does not follow that representational content plays no explanatory role within the theory. It is legitimate to ask which internal structures a computational vision theory, in particular, is concerned to describe and what constructing these structures does for the organism. These questions cannot be answered by appeal to purely syntactic or formal notions.

While not agreeing that representational (semantic) content plays no individuative role in a computational theory - a position she herself modifies somewhat (2003: 98f) - I take Egan's points about vision to carry over to matters linguistic, as will be made clear by (6b) below. Her subsequent suggestion that a distinction can be drawn between the mathematical and the cognitive functions that a particular mechanism is designed to compute, makes it legitimate to insist that information about the environment is what matters cognitively to the organism, and that the ways in which the mechanism provides the organism with information are in need of explanation. The fact that the system on occasion tricks its possessor into believing that something is there when it is not, does not alter this. That is the price the possessor pays for having it in the first place.

One step towards an explanation is by drawing a distinction between the generation of representations on the one hand, and the application of them on the other. As Dretske (1981: 197) puts it, a belief is "a kind of map by which we steer". The semantic content extracted is the map, the control it has over behaviour when applied is the steering. It is of prime importance for the representational account of language because it circumvents the question of causal dependency of representation on represented. It is, in fact, what is behind Barwise and Perry's (1983: 32) notion of "efficiency of language", the fact that the same expressions may be 'recycled' in a variety of situational contexts to say different things. Application of these ideas to the study of language presupposes that HLF is in fact a representational system. The next section explains what that is.

\section{REPRESENTATIONAL SYSTEMS ${ }^{1}$}

Dretske's credo is this: "In the beginning there was information. The word came later" (Dretske 1981: vii). It is a good credo. Among its many virtues is one to the effect that information is universal and omnipresent. It is there, whether or 
not someone or something responds to it or is affected by it. It cannot help being there. But it only becomes interesting when someone or something responds to it or is affected by it. In other words, when some system uses it for something. Systems that can do that are Representational Systems.

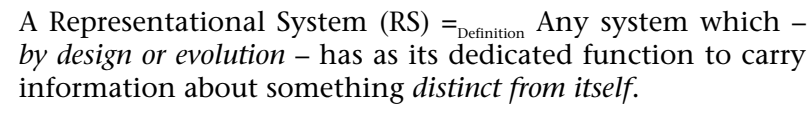

This definition explicitly mentions three characteristics of a RS - its origin, purpose, and direction - the latter two of which I shall comment on directly. The first - by design or evolution - need not detain us. I'll simply stipulate that HLF is the product of evolution, on a par with other cognitive systems. For a comprehensive presentation and discussion of various types of RSs, the reader is referred to Dretske's works listed in Footnote 1.

\subsection{Defining Characteristics of Representational Systems}

It is the function of a RS to carry information about something distinct from itself. A RS performs this function by entering a number of representational states, the relative sequentiality of which is determined by the chain of control (Beniger 1986). Although we can think of each state as $a$ representation, there is a particular output from the system that counts as the representation for its user, in the form of the semantic content of the signal. How the output is reached is opaque, or, differently formulated, the informational content of the various states the system has been in during the generation, is generally unavailable to the user. These are states to whose informational content the user normally has no conscious access, or may not even be "attuned", in Barwise \& Perry's terms.

Searle (1992: 52) argues that functionality is a normative concept. So it is, at least for the functionality of designed RSs. The claim that the function of maps is to carry information about locations is a normative claim. Maps can be used for many other things as well. Yet carrying information about locations is the dedicated function of maps - their raison d'être. When the normatively dedicated function of a designed system is to carry information about something distinct from itself, it is a RS. 
It is less clearly a normative claim that the function of visual systems is to enable the organism that has them to get visual information from its surroundings. As Marr formulates it, "the true heart of visual perception is the inference from the structure of an image about the structure of the real world outside" (Marr 1982: 68 italics added). ${ }^{2}$ When the evolutionarily dedicated function of a system is to provide information about something distinct from itself, it is a RS.

Dedicated functionality is a key notion in representation theory as here understood. It is the feature that determines whether a system is a RS or not. Many things carry information about something distinct from themselves. Cars, food, clothes may all carry information about particular lifestyles, for example, may even be thought to be signs for, or of, particular lifestyles, but they are not representational systems. It is not their dedicated function to represent anything, neither by evolution nor design. The criterion of dedicated functionality is what demarcates language from many other phenomena subsumed under sign systems by semiotics.

Observance of dedicated functionality likewise dissolves what Fodor (1990: 35) calls the problem of "nonsymmetry of representation". We may learn something about the weather by looking at a barometer - but we may also learn something about a barometer by looking at the weather. If it is a stormy day, we will know that the barometer is low, and yet the weather does not represent the barometer. Indeed not - it is not the dedicated function of weather to represent anything. The weather is not a representational system.

The third property of RSs - carrying information about something distinct from itself - is of particular importance to the thesis defended here, so much so that I feel inclined to invent a name for it, The Principle of Functional Displacement. Any external RS - as a physical phenomenon ${ }^{3}$ - carries information about itself. A map carries information about itself in terms of different colourings, types of medium (paper, cardboard, whatever), size, shape, etc. But it is not the kind of information that is of interest here, for it is not the kind of information that maps are functionally designed to carry. The information carried by maps that interests us in the normal course of events - that is, when we are not collectors of maps, but users of maps - is the information they carry about locations. 
In order to be able to respond in an informed manner to this sort of information we must know the key for interpreting the code in terms of which the system's expressive elements, the notational scheme on which they rely, perform their representational functions. We have to know that patches of blue on a map carry information about the location of water, that little crosses in green areas carry information about marshland, that yellow lines carry information about secondary roads, and so on. There is usually a key for the extraction of the semantic content these elements are supposed to have in a corner of the map - a key for interpretation. Although widely, even partly internationally, conventionalized, these elements may in themselves be subject to variation from one map to the next - different shades of blue and green, different density of crosses, different degrees of thickness of yellow lines. This does not affect their representational function, however, which remains constant across maps. It only affects the information carried by variations in the notational scheme.

The Principle of Functional Displacement claims that the same holds for internal representation systems, like HLF. This has wide ramifications for linguistic theory. It is readily agreed by proponents of most versions of generative theory that HLF generates representations. It is less readily agreed that the representations thus generated ultimately must be such that the information they carry is about situational structure and not about the structure of language itself. This is where representational theories differ most radically from derivational ones. While derivational theories assume that the generation of a sequence of representational states (Deep Structure, Surface Structure; Sstructure, D-structure, Logical Form, Phonological Form, etc., depending on version - see further section 5.1.1.), amounts to a restructuring of the previous one (viz. a derivation), representational theories regard each representational state as a product of the information generated at the previous one. The next section expands on the consequences of this difference.

\subsection{The Derivational-Representational Opposition}

There is some uncertainty over the consequences of choosing a derivational in favour of a representational approach to syntax within mainstream generativism, as expressed, for example, by Lasnik (2001). Sometimes it is implied that the two approaches are (terminological) variants of the same underlying reality (e.g. Chomsky 1995b: 150f), even to the point where it might 
be a matter of personal preference which option to adopt. Championing a representational over a derivational approach to syntactic theory, Michael Brody argues that there are both empirical and theoretical reasons why the two approaches cannot just be (preferential or terminological) variants. He establishes the following three-way distinction:

(4) i A derivational theory is nonrepresentational if the derivational operations create opaque objects whose internal elements and composition is (sic) not accessible to any further rule or operation.

ii A derivational theory is weakly representational if derivational stages are transparent (i.e. representations), in the sense that material already assembled can be accessed by later principles.

iii A derivational theory is strongly representational if it is weakly representational and there are constraints on the representations (weak sense) generated (Brody 2002: 22-3).

He claims that extant derivational theories are not purely derivational, but at least weakly representational in these terms. ${ }^{4}$ He continues:

\begin{abstract}
The real difference between derivational and representational approaches is different. The representational theory is a single level theory, all representations/derivations except the 'final' representation, LF, are eliminated - so conditions can only hold here. This is clearly one obvious way to constrain the multirepresentational theory: assume the existence of only a single representation, the one corresponding to the final output of the derivational system. Henceforth, I refer by representational theory unambiguously to the single level representational approach. To emphasize the representational properties of derivational theories I shall use the term "multi-representational".
\end{abstract}

The derivational approach constrains the multirepresentational theory differently, in a way that does not resolve the problems of the mixed theory. The derivational representational duplication now translates as the duplication between the final representation and the relevant aspects of all representations generated that carry the same information. Sisterhood and projection is duplicated at multiple levels by the effects of merge and chain by those of move [Footnote omitted]. The derivational theory ignores the problems of duplication and lack of restrictiveness, but suggests a different restriction. In this approach constraints like merge and move (which, as we have seen, are effectively equivalent to multilevel representational constraints) are individuated and are crucially required to operate in a sequential manner (Brody 2002: 25, italics added). 
The section I have italicized makes the point I want to emphasize, that syntactic representations in a derivational framework carry information about the system, hence just 'duplicates' itself. The point Brody is making, that a reduction of a "multi-representational" to a "single level representational" approach with the single level identified as LF, does not solve the duplication problem on its own, however, unless it is supplemented by a demand that the information this level is supposed to carry, is information about something distinct from the system that generated it. Even within Brody's framework of "Elegant Syntax", the single representational level envisaged does not do this. It is still a representational level at which systemic information is recorded.

The matter of numbers of levels of representations is not an issue. What is decisive is that a given representation, $R_{n}$, is - not a representation of $R_{n-1}$ at level $\mathrm{L}_{\mathrm{n}}$ - but a representation generated by the information carried by $\mathrm{R}_{\mathrm{n}-1}$ at $\mathrm{L}_{\mathrm{n}}$. Such representations, to be sure, are linguistic in some sense, but they are not representations of something as language structure. They are representations with a particular semantic content and - hence - representations of language structure as particular semantic types. It will take me too far afield to comment further on this particular issue here. Cf. Thrane (2004a, b, 2008) for further discussion. Instead I'll briefly present and comment on the thesis behind the representational approach to the study of HLF.

\subsection{The Extended Representational Thesis}

The thesis that Dretske introduces under the label The Representational Thesis in the Prologue to his (1995: xiii), from which the in-text quotations in the following section derive as well, comprises the two clauses (5b, c), to which I have added a third, (5a):

(5) a. All linguistic facts are mental facts.

b. All mental facts are representational facts.

c. All representational facts are facts about informational functions.

Dretske's thesis is claimed to amount to a representationally naturalistic theory of mind - and in particular to provide an inroad to the study of consciousness through "the baffling problems of phenomenal experience". It does not, as he admits, remove all obstacles to an understanding of phenomenal experience, or, 
indeed, to consciousness, but enough of them to be worth exploring. Whatever benefits such an approach may turn out to have, he says, "derive from conceiving of the mind as the representational face of the brain", Dretske's much more poignant version of Chomsky's "mind/brain" compound.

The motivation behind the thesis is the claim that not much insight into intentional phenomena is likely to accrue from more and more detailed study of the systemic properties of bearers of intentionality. For that, an account is needed of what these bearers $d o$ - in other words, a functional account. He draws an analogy to a camera. If you don't know what a camera is, to be told about $f$ stops, focal lengths, and shutter speeds won't help you understand it. You need to be told what cameras do. This is perhaps the single most decisive pronouncement that has motivated the present study. In order to make it clear why, I will elaborate on it.

First of all, Dretske's plea for functionality is not a plea for the kind of functionality associated with the ideas behind functional linguistics. Dretske is not, of course, saying, nor implying, that cameras are the way they are because they may be used to take pictures, or, even worse, that they are the way they are because they may be used to take pictures of people, or landscapes, or sports events, or whatever. He is just saying that in order to understand what a camera is, you need to know what its normatively dedicated function is, what it does whenever it performs, or in order to perform, whatever particular task it is called upon to perform within its dedicated functionality. So far, so good.

There is, however, another kind of functionality at play which Dretske does not explicitly consider, but which is important here. Cameras (old fashioned, analogue ones at least) have various knobs, levers and dials by which to calibrate for shutter aperture and speed, and for getting things in focus. Each of these performs a system-internal function, and they are entirely non-representational. You calibrate for focus by turning a dial, you regulate the speed of the shutter by moving a lever, you enlarge the shutter aperture ( $f$-stop) by twisting a knob, all depending on the make of camera. Precisely how these various gadgets are designed to allow the shutter and the lens to perform their dedicated functions is immaterial. What matters, again, is the function. However, an account of these functions enters into the overall account of the systemic side. Facts about them, 
again, are not representational facts, but facts about a representational system. Being told in detail about these functions will no more make you understand what a camera is than being told how they are implemented. It is the systemexternal functionality Dretske is after, the functionality of the camera as a whole, relative to input (light) and output (photo). This distinction is important if we want to extend it, metaphorically speaking, to the field of Generative Grammar and especially to the notion of representational system that it adopts.

\section{Representational ARCHIteCtURES}

This section will discuss various proposals for the internal organization, or 'architecture', of the system that is engaged in the processing of linguistically borne information. By using the singular 'system', I initially want to remain neutral with respect to the possibility that several distinct systems may be distinguished and justified. In particular, I want to remain neutral with respect to the question of where, and on what grounds, to draw the boundary between HLF and "other systems of mind" assumed to be relevant to language acquisition and use, so prominent in the branches of linguistic theory dominated by Chomsky. In the literature these topics are generally discussed in terms of the notion of "representational level". I'll avail myself of the vertical dimensionality implied by 'level' for discursive and illustrative purposes. I do not thereby suggest that the language system, or any other representational system, is shaped like a wedding cake.

The general idea that a representational system is internally organized in terms of levels may be illustrated from David Marr's study of vision. Four distinct, major levels of representation are recognized: the Retinal Image, the Primal Sketch, the $2 \frac{1}{2}-\mathrm{D}$ Sketch, and the 3D-model, though it was not concluded that there might not be others (e.g. Marr 1982: 275), as indicated in Figure 1. But these are the major ones, each with a distinct representational function, providing the next level 'up' with information in a suitable format for further processing. Likewise, for each level, algorithms are specified that will compute the appropriate functions. 


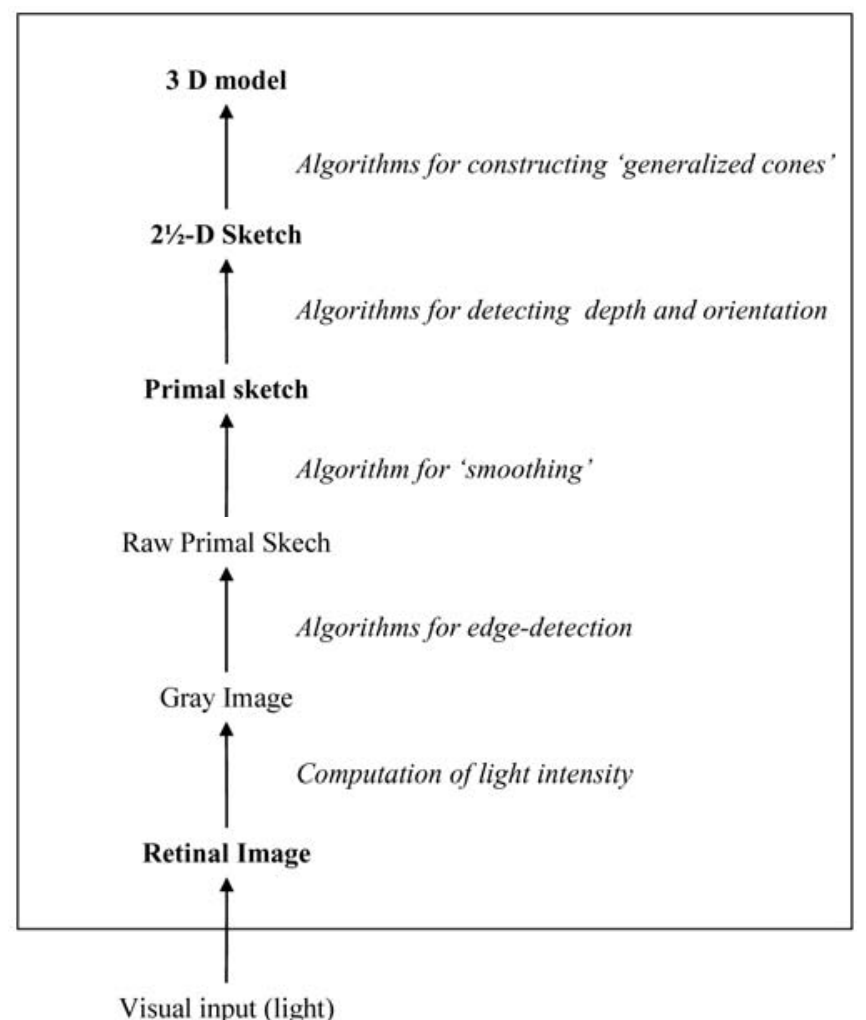

Figure 1. Representational Levels in Vision according to Marr

Two conditions determine the postulation of a particular representational level. As Chomsky points out (1986: 157) "the choice of levels of representation and their properties is an empirical matter, to be verified by their role in explanation". Representational levels are not 'given', it has to be shown how they are to be identified, and it must be shown how postulation of them will contribute to the overall explanation of the phenomenon under investigation. This presupposes that it is made clear what the overall representational process is taken to lead to.

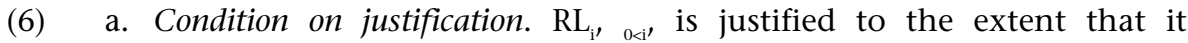
makes available the informational content that will allow the generation of $\mathrm{RL}_{\mathrm{i}+1}$ by the algorithm specified for the generation of $\mathrm{RL}_{\mathrm{i}+1}$.

b. Condition on identification. $\mathrm{RL}_{\mathrm{i}},{ }_{0} \leq_{\mathrm{i}}$, is identifiable in terms of semantic content - that is, in terms of the information extracted by the algorithm specified for the generation of $\mathrm{RL}_{\mathrm{i}+1}$. 
The condition on identification is formulated in terms of semantic content. This means that the process is irreversible. The inherent loss of information (digitalization) that accompanies any step from $\mathrm{RL}_{\mathrm{i}}$ to $\mathrm{RL}_{\mathrm{i}+1}$ is inescapable. It is, in fact, the precondition on any form of cognition. The condition on justification, on the other hand, just guarantees that the information extracted as the semantic content at level $\mathrm{R}_{\mathrm{i}}$ is indeed available at level $\mathrm{R}_{\mathrm{i}-1}$.

The requirements imposed on representational levels by these two conditions are quite strong. Relevance Theory (Sperber \& Wilson 1986, Carston 2002) takes our abilities of pragmatic development to constitute (at least) one representational level. Information structure in the sense of Lambrecht (1994) may be interpreted as constituting a representational level between that defined by Relevance Theory and certain 'lower-order' level(s) of grammar in terms of which HLF formally organizes informational content, perhaps even encroaching on the latter. However, as formulated, these two theories do not completely satisfy the condition of justification (6a). Both assume that at least some information not provided by 'lower-order' representational levels is necessary and available for their generation. Such extra-linguistic information must be disregarded if a consistent representational view is to carry through. The suggestion, in other words, is that we seek to explore as far as possible the idea that these 'pragmatic' abilities generate identifiable higher-order representations on the basis of informational input restricted to other identifiable, but 'lowerorder', levels of representation. The following section will look at a sequence of generative proposals for the architecture of the language faculty as constituted by a number of such 'lower-order' representational levels in terms of the two conditions in (6).

\subsection{Chomskyan Models of the Language Faculty}

Chomsky's programme has consistently been pursued on the basis of a number of assumptions, some of which were listed in (3). One, held "at least since Aristotle", is that language is "form with a meaning" (Chomsky 1980: 61 - cf. (3c)). The second is that the human language faculty is an innate, autonomous system, with interfaces towards other systems of mind - cf. (3a). These are constant factors behind the various implementations of Chomsky's theory of language. The number, relative organization, and, particularly, the informational content of the representational levels proposed for these 
implementations may be decisive for particular versions of the theory, but they are only constant to the extent that they help explain, in different ways, aspects of the relationship between form and meaning, the content of (3c), within the constraints set by the content of (3a).

\subsubsection{Representational Levels}

The set of linguistic levels inherited from the earliest proposals of Transformational-Generative Grammar in the Standard Theory (ST) of Aspects (Chomsky 1965: 222-3, note 2) comprised phonetic, phonological, morphological, phrase structure and transformational levels, explicitly seen as forming a hierarchy. These are referred to as "representational levels" already in Chomsky (1955: 105), but the notion of "representation of utterances" behind his usage there is fairly obviously of an instrumentalist kind later dismissed. What would be more in accord with later concepts of representation is the relative organization and informational content of the levels of Deep and Surface Structure. Through a process of lexical insertion, the system of base-rules generates the level of Deep Structure which carries information needed for semantic interpretation. The system of transformational rules maps phrase marker onto phrase marker, culminating in a Surface Structure which carries information needed for phonetic interpretation (Figure 2). The transformational steps changing one phrase-marker into the next would satisfy the conditions (6) and thus constitute (intermediate) representational levels. The Lexicon is not, in fact, a representational level, but an informational source. In the early models it provides phonological form to complex symbols of features through lexical rules, in later models (from GB) it provides initiating information in the manner of light in Marr's account of vision. As such it is part of the language faculty, but otherwise its status is only intermittently the object of particular concern. In the following illustrations I will include the representational levels proposed in a box, with the algorithmic procedures required for their generation in italics, leaving the Lexicon outside. 


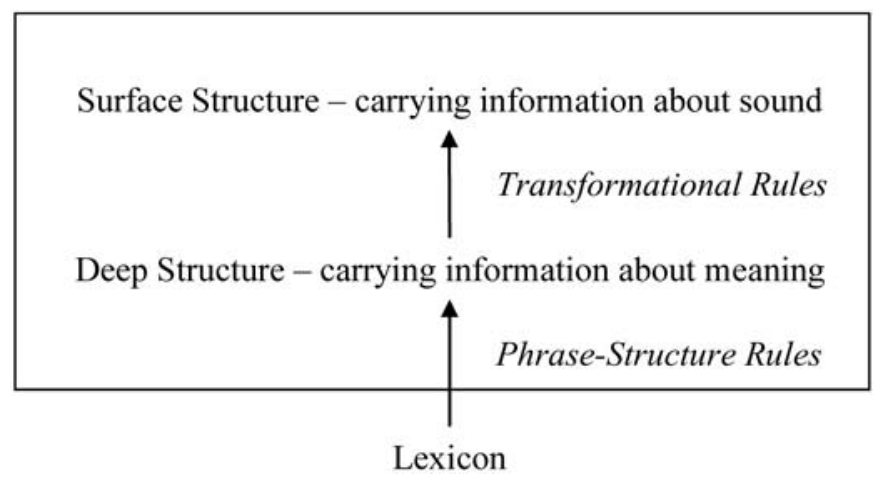

Figure 2. Representational Levels in ST

There is a high degree of cleanliness and representational rigour about this arrangement. It was criticised in the mid-to-late 1960's on the grounds that the irreversibility of transformational derivation was unacceptable. As the Condition of Identification states (cf. 6b), this particular piece of criticism was misguided, stemming from lack of discrimination between information and meaning. Transformational rules (T-rules) were "meaning-preserving", thus not supposed to add or subtract any information needed for semantic interpretation, which was all supposed to be available at Deep Structure. However, certain semantically 'empty' elements, like expletives, might be inserted by T-rule. Similarly, structures carrying all the information needed for phonetic and prosodic interpretation were generated by T-rules, essentially through linear reorganization of elements identified at Deep Structure, controversially implying that Deep Structures were, themselves, somehow linearly ordered. The arrangement gave rise to 'transformational families' of sentences, sentences derived from the same lexical input and the same Deep Structure, but taking on different Surface Structure forms by undergoing different transformational histories. Semantic interpretation was identified with truth-functional content, so Deep Structure representations were seen as providing a grammatical level of description corresponding fairly closely to the logical notion of 'propositional content'.

The cleanliness of this picture was disturbed in the Extended Standard Theory (EST - Chomsky 1968, 1970, 1972). Questions of 'lexical' vs. 'non-lexical' transformations were prominent at the time, as was the question of identifying the proper representational level(s) for the semantic interpretation of a fairly 
narrowly circumscribed, but varied, body of linguistic facts. Presupposition, focus, certain anaphoric phenomena associated with contrastive stress, the interpretation of modal and temporal auxiliaries were among areas singled out for which a surface structure location of interpretive information seemed to be required (Figure 3 ).

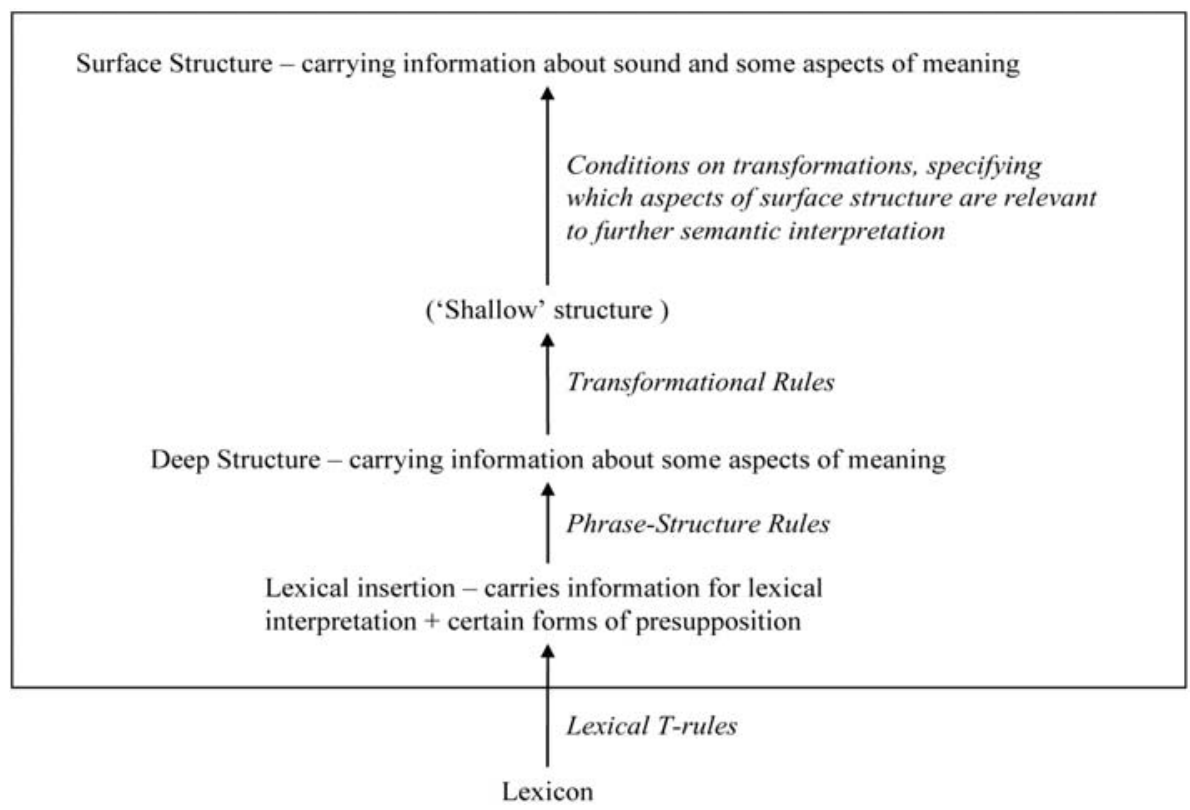

Figure 3. Representational Levels in EST

The information for semantic interpretation still residing at Deep Structure was, in particular, information needed to identify grammatical relations by configurational means, and thematic relations associated with selectional properties of lexical items introduced there, but also the various presupposed pieces of information carried by lexical items like assassinate, dissuade, etc., which Generative Semantics had been proposing as constituting legitimate phrase-markers to be replaced by lexical items by lexical T-rules, and which the lexicalist position taken by Chomsky in EST just regarded as elements of meaning with no particular grammatical import and thus just introduced with the lexical items themselves. More 'disruptive' of the orderliness of ST, however, was information needed for quantifier interpretation and prosodic matters of focus and anaphora. In order to account for this, a somewhat informal representational 'level' of "shallow structure" was sometimes mentioned as a late 
stage in the course of the derivational history of a sentence (e.g. Chomsky 1972). At, or through, this level, a set of general conditions on transformations was defined, specifically determining what information without explicit Deep Structure origin must be located at Surface Structure, for purposes of semantic interpretation.

With the advent of trace-theory in the Revised Extended Standard Theory (REST - Chomsky 1976), a device for keeping track of information was at hand which allowed all aspects of meaning to be located at the representational level of Surface Structure, resolving at the same time problems with the standard notion of anaphora in favour of co-indexation of traces with their antecedents. Tracetheory likewise extended the coverage of interpretation of scope of quantifiers. Issues of lexical transformations having been settled by EST, the Lexicon is again just a part of the base-rule system (Figure 4):

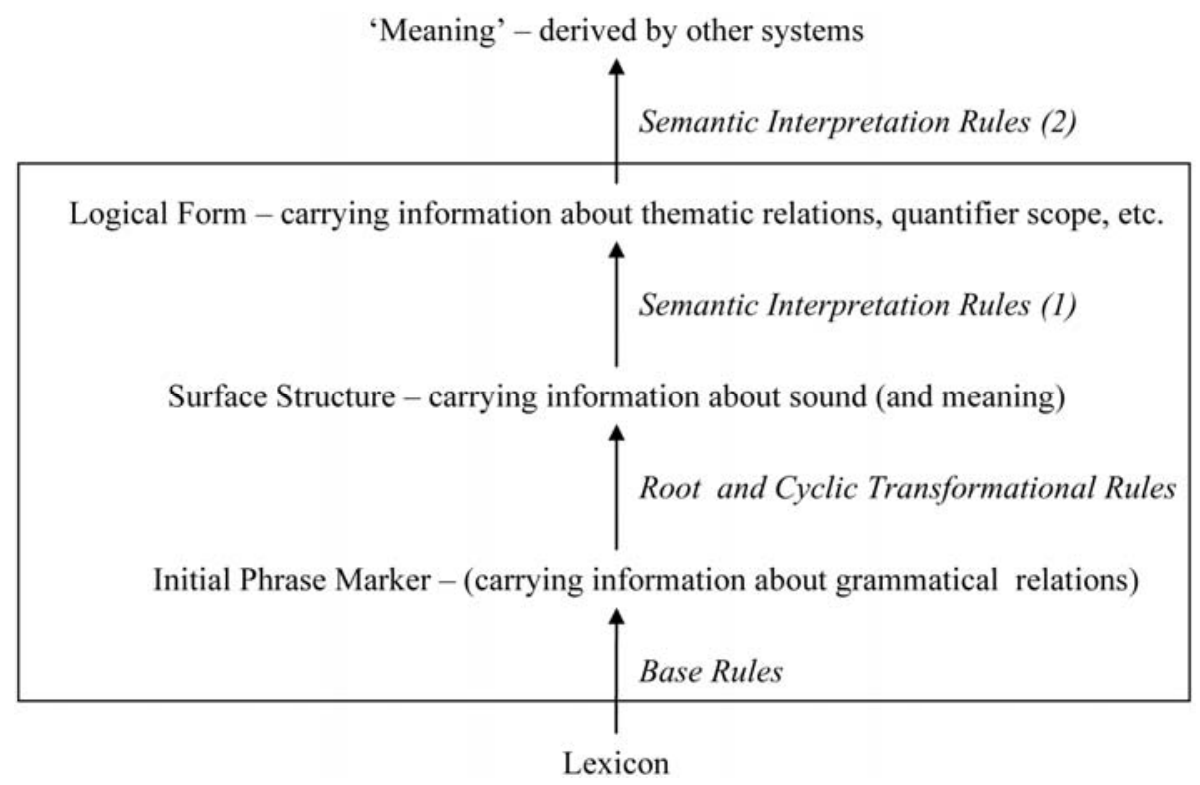

Figure 4. Representational Levels in REST

REST saw the introduction of the term 'logical form', supposed to identify a level of representation carrying information about "bound anaphora, scope, thematic relations, etc." The logical form was "subject to further interpretation by other semantic rules (SIR-2) interacting with other cognitive structures giving fuller representations of meaning" (Chomsky 1976: 105). Note, in particular, that 
information for the identification of thematic relations is now located at the level of logical form, even though it is still assumed to be introduced as a function of selectional properties of lexical items as elements of the "Initial Phrase Marker". Indexed traces provided the necessary link.

The conceptual shift towards a Principles and Parameters (PP) framework initiated by GB (Chomsky 1981), which essentially replaced the concept of rules with a set of principles that internal grammars must meet, and which reinterpreted Universal Grammar as a reservoir of parameters whose values are set by experience in Chomsky (1986), was in part motivated by the interpretation of various kinds of operators, quantified NPs and the wh-operator, which seemed to require access to information located at a more abstract level than that provided by S-structure. Models of the language faculty are now presented in terms of a T-model (Figure 5).

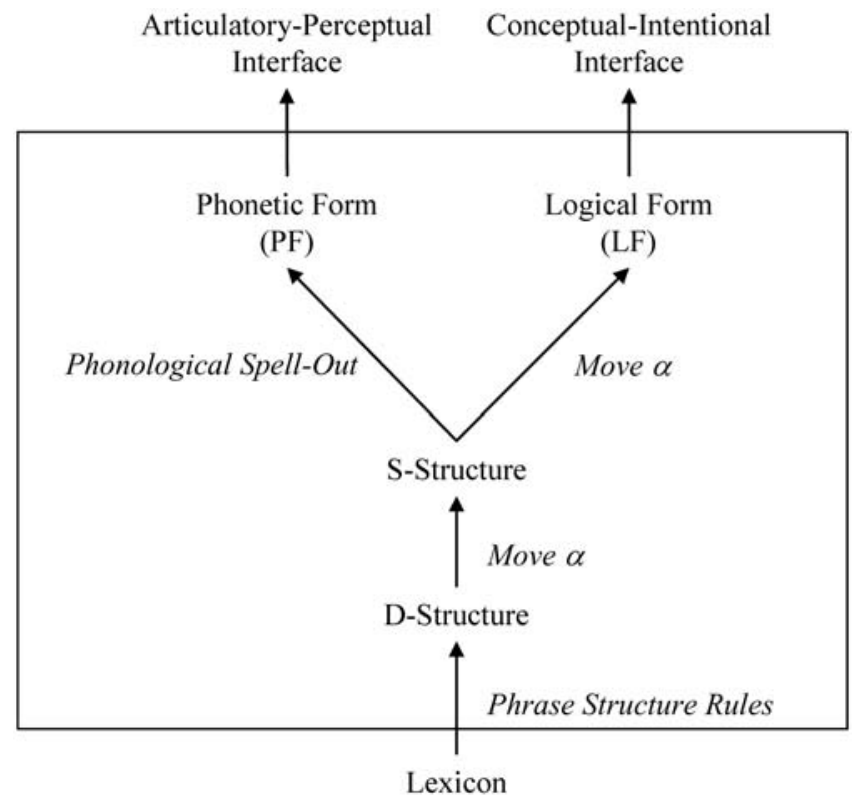

Figure 5. T-model of GB etc.

Chomsky (1981) is the most comprehensive statement of the technical framework of Generative Grammar since Aspects (1965), and it is perfectly possible to use it as a standard for a descriptively adequate grammar, without much concern for its potential adequacy for explaining its relationship with biological equipment or mental capacities, as documented by textbooks like 
Haegeman (1991). There, initially two representational levels are envisaged, DStructure and S-Structure. Both carry information about syntactic properties, with predicate-argument and thematic relations located at D-Structure, linearity determined at S-Structure. Logical Form (LF) is introduced as a late, third representational level carrying information needed for truth-functional interpretation. This particular organization favours a production rather than a reception model of language structure. LF is essentially an isomorphism on SStructure, and movement operations at LF leave no overt phonological traces. The flow of information between levels is technically implemented as the formation of chains, syntactic objects consisting of antecedents and co-indexed traces.

The T-model is the general format which the Minimalist Program (MP) took over (Chomsky 1993), except that the levels of D-structure and S-structure are no longer identifiable as unified levels of representation. Likewise, 'Move $\alpha$ ' as the sole syntactic process is abandoned, replaced by a sequence of distinct operations which in ordered co-operation generate structures at PF and LF from an initial selection of elements from the Lexicon, a "numeration" or "lexical array", through a sequence of intermediate derivational steps. These are no longer deterministic, but operations that build structure on the basis of an indeterministic assignment of "strength" to the various grammatical feature bundles that drive them, and thus no longer satisfy the conditions on representational levels of (6) - Figure 6. 


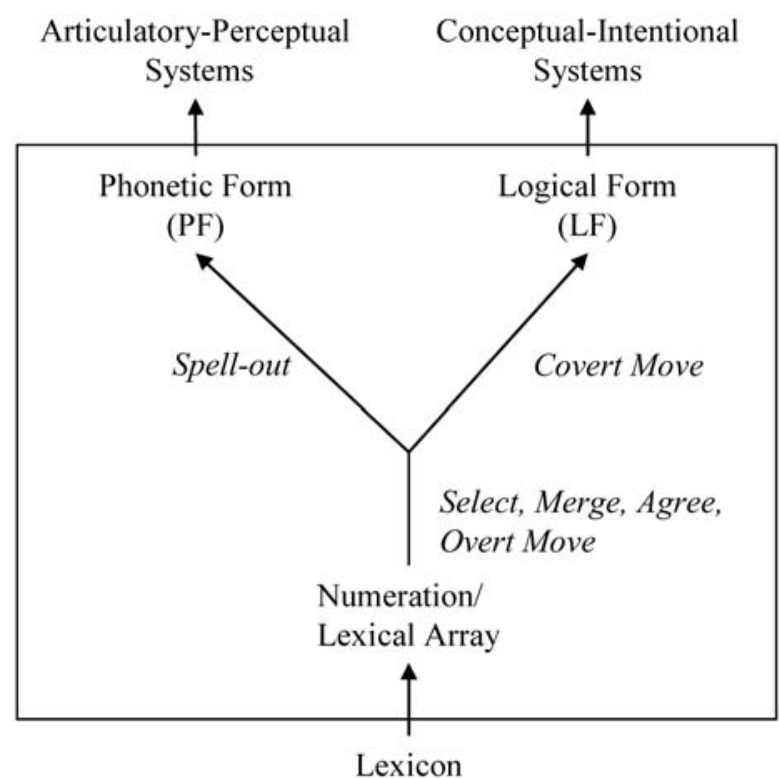

Figure 6. Representational Levels in MP

Summarizing the main point of this somewhat heavy-handed tour de force through various models of the language faculty, the representational level needed for the assignment of (truth conditional) meaning to strings of sound has gradually shifted from Deep Structure through "Shallow Structure" to SStructure to the level of LF, an isomorphism on S-Structure. The motivation for these shifts has invariably been claimed to be empirical, and justification for them has been sought in extended coverage of data, both in terms of number of languages and of language internal types of expression taken into account. In this way, they have contributed immensely to the understanding of the complexities of language structure, setting new standards for descriptive adequacy of proposed grammars. However, while not denying the importance of the empirical facts to be explained, I will nevertheless claim that motivation for the technical innovations and changes internally defining the various versions, has been weak. They have been aimed at consolidating the flow of information between levels of representation admitted inside the boxes, hence system internally, reduplicating information available at earlier levels. Many of them have indeed been jettisoned as "notational artefacts" under requirements imposed by shifting theoretical concerns. One of the most radical proposals in this respect is the rejection of X-bar theory in favour of "bare phrase structure" (Chomsky 1995c), a proposal that reflects the somewhat unstable ontological 
status of such theoretical constructs as V-bar, $v \mathrm{P}$, etc. More relevantly, it is a proposal that favours a derivational over a representational approach, thus reflecting Chomsky's view of the aim of linguistics.

\subsection{The Aim of Linguistics}

The aim of linguistics, on Chomsky's account, is to describe and explain the various levels inside the boxes in Figures 2-6 above, given a lexical input. What is supposed to happen from one stage to the next - crucially, in all models, involving movement in some form - is regarded as a derivation, that is, a reshuffling at level $L_{n}$ of the information available at level $L_{n-1}$. The information preserving requirement is codified as the Projection Principle, which informally states that all information originating in lexical items is syntactically represented, and that it is represented at all levels. The boxes and their contents are seen as forming a closed system, variously and progressively described as "a device of some sort for producing the sentences of the language under analysis" (Chomsky 1957: 11), "the knowledge of the language that provides the basis for actual use of language by a speaker-hearer" (Chomsky 1965: 9), "the language faculty" (Chomsky 1980: 59), "a highly structured theory of UG" (Chomsky 1981: 3-4), "the basic elements of I-language" (Chomsky 1986: 51), and a "notion of structure" (Chomsky 1995b: 3), to culminate in the following formulation that deserves special attention:

\footnotetext{
The study of language tries to develop bodies of doctrine with an eye to eventual unification. Its constructs and principles can properly be "termed mental," and assumed to be "the result of organical structure" - how, it remains to discover. On these aspects of the way language engages the world, there is little more to say. (Chomsky 2000: 168, italics added).
}

I take these various formulations to circumscribe the language faculty as understood in section 5.1. However, in a highly controversial and widely discussed article co-authored with Hauser and Fitch, Chomsky has latterly introduced a distinction between a "narrow" (FLN) and a "broad" (FLB) conception of the language faculty. FLB is assumed to include "a sensory-motor system, a conceptual-intentional system, and the computational mechanisms for recursion, providing the capacity to generate an infinite range of expressions from a finite set of elements", whereas FLN by hypothesis "only includes 
recursion and is the only uniquely human component of the language faculty" (Hauser, Chomsky, and Fitch 2002: 1569). They explicitly exclude memory from FLB together with other organism-internal systems that are necessary, but not sufficient, for language (2002: 1570) - cf. the comments on the Lexicon above. Not much of the content of the five figures 2-6 is left, even in FLB. I agree with Pinker and Jackendoff (2005) in their near-total rejection of recursion as the sole and central hallmark of language. Consequently, HLF should be taken as summing up the boxed elements of figures 2-6.

Whether HLF, FLB or FLN is assumed as the content of the language faculty, it could be argued that Chomsky has so far failed to give a single, coherent, unified and universally accepted account of it. As Gazdar and his colleagues noted already in 1985, if Chomsky's programme is a branch of psychology or biology at all, "it is so far the branch with the greatest pretensions and the fewest reliable results." (Gazdar et al. 1986: 5). As would appear from the last Chomsky quote above, however, this is just a matter of time - "how, it remains to discover". What's more, it is not necessarily linguistics that has failed to deliver:

\begin{abstract}
Any progress towards this [Minimalist - TT] goal will deepen a problem for the biological sciences that is already far from trivial: how can a system such as human language arise in the mind/brain, or for that matter, in the organic world, in which one seems not to find anything like the basic properties of human language? That problem has sometimes been posed as a crisis for the cognitive sciences. The concerns are appropriate, but their locus is misplaced; they are primarily a problem for biology and the brain sciences, which, as currently understood, do not provide any basis for what appear to be fairly well established conclusions about language. Much of the broader interest of the detailed and technical study of language lies right here, in my opinion. (Chomsky 1995b: 1-2, italics added)
\end{abstract}

The faculty of language is a property of the "mind/brain", Chomsky's compound expression to deflate philosophical dualism. This may be a desirable mode of expression for a naturalistic approach, committed to a rejection of a legitimate distinction between them; but it has the effect of blurring what might be some important edges. Instead of deflating mind-body dualism, it creates a slipway for linguistic usage to slide effortlessly between them, at least in one direction: "Naturalistic inquiry into the mind yields theories about the brain, its states and properties: UG, for example" (Chomsky 2000: 103, italics added). The "crisis" 
mentioned in the last quotation above is elaborated in the course of the page or so of text following it, and it is then suggested that "[v]arious remedies have been proposed to deal with this crisis. One is the proposal that "the mental is the neurophysiological at a higher level", dismissed as being "now a hypothesis about the neurophysiological, not a characterization of the mental" (Chomsky 2000: 104). Inquiry into the brain, in other words, does not yield theories of the mind. Yet once again, it may be wondered that other naturalist proposals are not considered, in particular Dretske's dictum that "the mind is the representational face of the brain". This is as explicitly nondualist as one might wish, but it retains a certain principled manner in which talk about the system can be distinguished from talk about what the system does.

No doubt legitimate objections can be raised to Chomsky's claim that providing a theory of the human language faculty is the goal of linguistics. These would be objections I would not know how to respond to, except by disagreement. Another kind of objection might be that the goal is too ambitious, that it constitutes a "mystery" rather than a "problem", in Chomsky's (1976) terms. This would be of a kind with Chomsky's own objection to the possibility of formulating a coherent theory of interpreting, for example, on the grounds that it would have to amount to a theory of successful communication and as such be "far too complex and obscure to merit attention in empirical enquiry" (Chomsky 2000: 70). Complexity should not be a deterrent. On his own frequent insistence, language is even highly "complex" - so the argument would just have to maintain that the language faculty is "obscure", not an invalid proposition in itself. A third kind of objection is the one inherent in Gazdar's criticism that despite concerted effort, few tangible results have appeared to support the claim that linguistics is a subbranch of psychology and biology, a view apparently sanctioned by Chomsky himself in the second italicized passage from (1995b) above. Since Gazdar and Chomsky wrote, results have appeared, though many still remain contentious, for example the evidence from studies on the KE-family (Alcock et al. 2002, MacWhinney 2002) and the role of FOXP2 as a 'language gene' (Vargha-Khadem et al. 2005). None of these studies are conducted from explicitly Chomskyan points of view, but others are. One such is the study by Christensen (2005). Let me therefore briefly summarize some of his relevant findings and proposals. 


\section{The Language Faculty in Brain Studies}

Apart from careful and detailed linguistic analysis of negation in a variety of genetically and typologically distinct languages, the research reported on in Christensen (2005, expanded in Christensen 2008, and summarized in the present volume, to which Danish readers are referred) provides a state of the art survey on neurolinguistic work related to movement phenomena, in addition to reports on two kinds of brain scanning experiments designed and carried out by himself. The focus on movement - the constant and crucial ingredient in Chomsky's overall derivational procedure - makes Christensen's study particularly apt as a testing ground for the neurophysiological implementation of Chomsky's theoretical claims.

One aim of the study is to find experimental evidence to sustain what Christensen calls the Domain Hypothesis, a hypothesis that takes CP, IP, and VP as three distinct but interrelated representational domains as its point of departure. As such it takes up the challenge posed by Marr's third level of explanation to be satisfied by a computational theory, the level of implementation. In contrast to the present paper, Christensen's is loyal to the technical aspects of Chomsky's theory. It is firmly grounded in a version of Minimalist theory including derivation by phase, supported by analytical tools from Optimality Theory.

The triggering data for the study is the phenomenon of NEG-shift which to varying degrees is an integral part of the narrow syntax of the Germanic languages except English, here rudimentarily illustrated from Danish; (7a) has undergone NEG-shift, (b) has not. They are strictly synonymous, but (b) is by far the preferred version in modern spoken Danish.

What matters here is the fact that NEG-shift, under given assumptions, ${ }^{5}$ is undoubtedly an overt movement operation in Danish. The question is if it has any correlation with increased neuronal activity in any of the core syntactic areas of the brain, notably Brocca's area, by presumption detectable by means of various methods of brain scanning. 
The linguistic data comprises four types, NEG-shifted and non-NEG-shifted sentences, wh-questions and yes/no-questions of the same number of words, along the rough structural lines of (7):
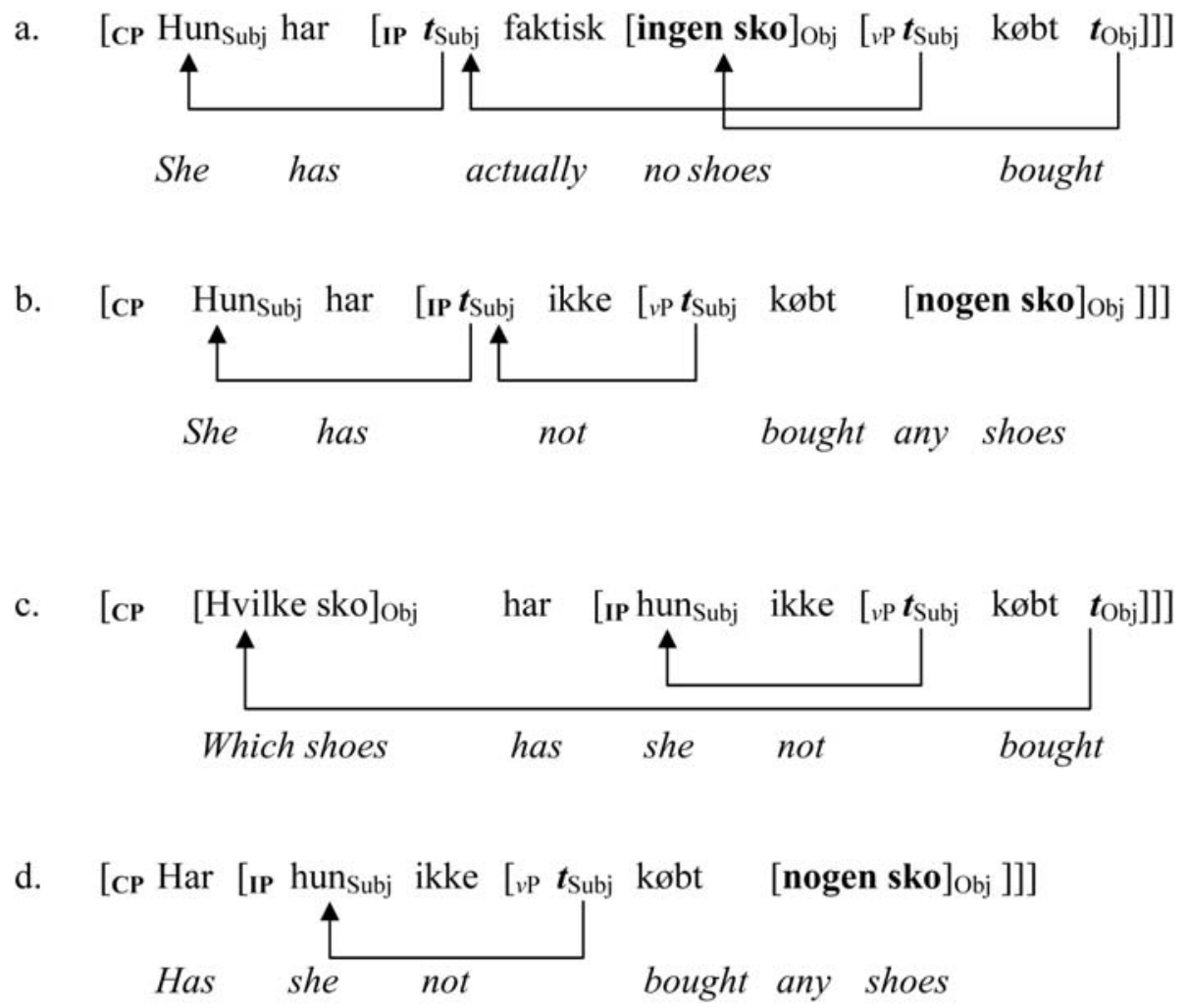

The reason for this particular choice of structures is that the landing site for the NEG-shifted object in (a) is a position inside the IP-domain, whereas for the whmoved object of (c) it is inside the CP-domain. The occurrence of faktisk 'actually' in (a) is due to the demand for an even number of words. One interesting finding, incidentally, was that there was a significant difference in response time towards 5-word as against 6-word sentences when it was a matter of absence vs. presence of a finite Aux, but not when it was a matter of ingen 'no' vs. ikke ... nogen 'not ... any' (p. 274).

Christensen is careful to distinguish between various kinds and levels of modularity. He dissolves the "mind/brain" compound, claiming that the 
language faculty, as a mental phenomenon, is a unitary system, separate from "other systems of mind" - vision, proprioception, etc. In contrast, its implementation in the brain need not be - in fact, is not. It is a distributed syntax network, different parts of which are activated depending on what kind of linguistic task is called for. However, this does not entail that we need find 'corresponding' modules at the level of implementation. This is a fairly standard generative view. What may not be quite so standard is his commitment to the Domain Hypothesis, which states that movement is sensitive to the syntactic target domain (CP, IP).

The empirical basis for the conjecture of the Domain Hypothesis is the important, though negative, finding that NEG-shift apparently triggers no increased activity in the core syntactic areas. Assuming that movement in general should be predicted to trigger such increase, that both wh-movement and NEG-shift are (overt) movement operations, and given the experimental result that whmovement does trigger increased activity in Brocca's area, lack of it in connection with NEG-shift is in need of independent explanation. Hence the Domain Hypothesis.

Subjects are supposed to originate in the VP-domain (cf. 7) and summarily move to the canonical subject position in IP, in both declaratives and interrogatives. If no other constituent is moved to CP-Spec, subjects are moved further into CP to satisfy the Danish V2 requirement in declaratives, whereas they stay in IP in interrogatives (cf. 7a, b vs. c, d). These facts are mentioned (p. 293). However, there is no explicit comparison of the two tasks that do not involve object movement $(7 \mathrm{~b}, \mathrm{~d})$, although this would seem to bear directly on the Domain Hypothesis. If the Domain Hypothesis is correct, we would predict activation in Brocca's area in response to declaratives like (7b), where movement of the subject (ultimately) targets the CP-domain, but not in response to yes/noquestions like $(7 \mathrm{~d})$, where it just targets the $I P$-domain. Differences of activation in these tasks would therefore provide evidence for domain boundaries, if not (necessarily) for the Domain Hypothesis itself.

These consequences are strictly the concern of linguistic theory, not of the neurolinguistic theory of mind-brain correlation. But there is one consequence which is the concern of neurolinguistic theory that output from operations in 
the various syntactic domains is required to interface with "other systems of mind" during derivation. It is no doubt correct that linguistics and neurolinguistics operate with different magnitudes of conceptual finegrainedness ('The Granularity Mismatch Problem' - p. 247) and with radically different basic entities ('The Ontological Incommensurability Problem' - p. 248). But that does not affect this particular issue, which can be formulated as a problem on either side of the linguistics - neurolinguistics divide. It is a question of information.

\begin{abstract}
Both [types of tasks - the distinction between them not relevant to the point at issue - TT] involve syntactic processing, and I shall argue that interfacing between core syntax and other cognitive domains is reflected in bilateral activation patterns with focal points determined by type of information involved, for example thematic information in the right hemisphere. (Christensen 2005: 253, italics added)
\end{abstract}

He continues:

\begin{abstract}
At various points during the derivation, the computational system interfaces with higher cognitive systems. That is, partial syntactic representations are mapped onto thematic/semantic, grammatical, and pragmatic (information-structural/discourse related) representations (unless otherwise stated they are all normally subsumed under the label of LF [Logical Form - TT]). (p. 255)
\end{abstract}

The last parenthesis causes ambiguity. What is the antecedent/referent of "they ... all" in the last line? It may be either the "partial syntactic representations" or the "thematic/semantic, grammatical, and pragmatic (informationstructural/discourse related) representations". On the former reading, the partial syntactic derivations have reached LF-form before transfer. On a conservative interpretation, this suggests that they provide information for the generation of higher order representations of a thematic/semantic, grammatical, and pragmatic nature, which are thus 'outside' the domain of LF, and hence presumably - HLF. On the latter reading, higher order representations of a thematic/semantic, grammatical and pragmatic nature are already generated at LF for the partial syntactic representations to 'map onto' - hence part of HLF.

On either interpretation, however, more information is needed for the generation of higher order representations than is provided by the core syntactic 
processes. Some of it, true, may derive from conceptual/semantic content of whatever lexical items were in the numeration, but much of it is not. If Carston (2002: 334ff) is right in regarding, for example, processes of broadening and narrowing of conceptual content 'on-line' as forming part of a representational level towards the construction of propositional content, supervening on those provided by the core syntactic processes, then the LF interface perhaps becomes nothing but a portmanteau with indiscriminate content.

To conclude, the results of Christensen's scanning experiments are important, but do not provide much support for the theoretical linguistic claims made. In particular, the question of domain boundaries, if the Domain Hypothesis is to be upheld, is not trivial. Discussion of these various issues may be fruitful for the purpose of refining and fine-tuning current theoretical assumptions. The problem is that particular choices in these areas seem not to have any empirical consequences, nor do they seem to be refutable by E-linguistic evidence or by neurolinguistic evidence of implementation. What Christensen's scanning experiments do seem to support, however, are claims against monolithic conceptions of the language faculty, and in particular against a too comprehensive and indiscriminate conception of the level of logical form.

\section{CONCLUSION}

The preceding sections have argued that the mainstream generativist position on the human language faculty is a consequence of its failure to distinguish between the system and its functionality, persistent adherence to the basic assumptions of (3), the degree and kind of idealizations that underlie the programme, and, most importantly, from the investigative consequences drawn from these idealizations. Chomsky himself has consistently argued for regarding the language faculty as an "organ", autonomous relative to other systems of the "mind/brain", on a par with the visual system. It may even turn out to be true; or, for all we know, it may turn out to be true in any combination of ways between AUTOSYN, AUTOGRAM, and AUTOKNOW ${ }^{6}$ that Newmeyer (1998) discusses in detail. But this would be a claim about the system. Adoption of any autonomy thesis legitimizes a strategy of investigation that targets what amounts to the systemic properties of HLF. This is not a question of how "language engages the world"; nor is it a question of "methodological dualism". It is a question of how language engages other internal faculties, even though it might be autonomous in 
any way we like. It is a matter of flow of information, not within the system, but towards 'other systems of mind'.

By insisting on this strategy sanctioned by the autonomy thesis, one may legitimately dismiss any question of 'external' - yet mind-internal functionality that might arise. Any question of what the language faculty does whenever it does what it is supposed to do, is answered in system-internal terms. The language faculty generates representations. This is not in doubt. But the information that these representations are presumed to carry is information about the system that generates them. This is a major point at which Dretske's and Chomsky's views diverge. For a system to be a representational system it must carry information about something distinct from itself - or so Dretske and Marr tell us. Marr's theoretical account may avail itself of "blobs" and "edges", and may specify the mathematical workings of the system as computing a convolution with a Gauss-function - but in the end it aims to explain why what we see is a box and not a tree. This is the point of Egan's insistence on the legitimacy of distinguishing between the mathematical and the cognitive functions computed, discussed above (section 3.5). It is, in fact, the Principle of Functional Displacement.

What Chomsky currently tells us about the faculty of language understood as a system may indeed be true - at present there is no way of knowing. Suppose it is. It then constitutes a body of facts about a system - what its elements are, how they are organized, how they function relatively to each other. But they are not representational facts, hence not mental facts. They are facts about a representational system, hence 'brain' facts, even though 'brain' here is not a matter of neurons and synapses, but rather of a closed system of theoretical constructs. It may or may not be the case that the 'real' brain sciences are lagging behind with respect to tangible results to support the findings of linguistics, as Chomsky suggests. Nevertheless, it would be welcome for the predictions made by linguistics to have some kind of neuronal effect that could at least be sustained by results from fMRI-scannings and the like. As shown above, at least some of them do not. The current generative description of the language faculty corresponds to the description of a camera in terms of $f$-stops, shutter speeds, ASA-numbers, and focal length that Dretske (1995) dismisses as relevant to a deeper understanding of cameras (4.3). 
By way of conclusion, an extension of this analogy in a somewhat radical manner may be used to formulate three positions, thereby sharpening the relative positions of Chomsky and Dretske vis à vis a rough 'functional linguistic' one. Chomsky insists that the only relevant and interesting thing to be gained from scrutiny of a camera's outputs - the pictures it takes - is the support it gives or fails to give to predictions about the technical properties of the camera and how they exchange information. It is possible to be sceptical about the falsifiability of statements flowing from this procedure. Dretske insists that the interesting question is what a camera must be able to do for there to be pictures (of whatever) in the first place. Focus on this kind of functionality will constrain the technical space within which it can be implemented, but is mute on specific issues of implementation, which may vary from one camera to the next.

The 'functional linguistic' interest in cameras on this analogy is incidental, at best that they meet required, but technically unspecified, standards of quality of implementation to a degree that makes it possible to determine from the pictures they take, who or what is depicted. That's what matters. This is no doubt a desirable practical interest - what would be the point of taking pictures if you can't see what they are pictures of; but it is not an interest that helps us understand cameras, or how they work. And if that is what we want to be able to do, my money is on Dretske, rather than on Chomsky.

\section{REFERENCES}

Alcock, Katie, Richard Passingham, Kate Watkins, Faraneh Vargha-Khadem (2000), "Oral Dyspraxia in Inherited Speech and Language Impairment and Acquired Dysphasia", in: Brain and Language, 75, pp. 17-33.

Barwise, Jon, John Perry (1983), Situations and Attitudes, Cambridge, Mass.: Bradford.

Beniger, James R. (1986), The Control Revolution. Technological and Economic Origins of the Information Society, Cambridge, Mass.: Harvard University Press.

Brody, Michael (2002), "On the Status of Representations and Derivations", in: Epstein, Samuel David, T. Daniel Seely (eds.) (2002), Derivational Explanation, Oxford: Blackwell, pp. 19-42.

Carston, Robyn (2002), Thoughts and Utterances: The Pragmatics of Explicit Communication, Oxford: Blackwell.

Chomsky, Noam (1955), The Logical Structure of Linguistic Theory, New York and London (1975): Plenum Press.

Chomsky, Noam (1957), Syntactic Structures, The Hague: Mouton. 
Chomsky, Noam (1965), Aspects of the Theory of Syntax, Cambridge, Mass.: MIT Press.

Chomsky, Noam (1968), "Deep Structure, Surface Structure, and Semantic Interpretation", in: Chomsky, Noam (1968), Studies on Semantics in Generative Grammar, The Hague 1972: Mouton, pp. 62-119.

Chomsky, Noam (1970), "Remarks on Nominalization", in: Studies on Semantics in Generative Grammar, pp. 11-61, The Hague 1972: Mouton.

Chomsky, Noam (1972), "Some Empirical Issues in the Theory of Transformation Grammar", in: Studies on Semantics in Generative Grammar, pp. 120-202, The Hague 1972: Mouton.

Chomsky, Noam (1972b), Studies on Semantics in Generative Grammar, The Hague 1972: Mouton.

Chomsky, Noam (1976), Reflections on Language, London: Temple Smith.

Chomsky, Noam (1978), “On Binding" (draft; subsequently published in:) Linguistic Inquiry, 11.1 (1980), pp. 1-46.

Chomsky, Noam (1980), Rules and Representations, New York: Columbia University Press.

Chomsky, Noam (1981), Lectures on Government and Binding. The Pisa Lectures, Dordrecht: Foris Publications (= Studies in Generative Grammar, Vol. 9).

Chomsky, Noam (1993), "A Minimalist Program for Linguistic Theory”, in: Hale, Kenneth, Samuel Jay Keyser (eds.) (1993), The View from Building 20: Essays in Linguistics in Honor of Sylvain Bromberger, Cambr. Mass.: MIT Press, pp. 1-52.

Chomsky, Noam, (1995a), "Language and Nature", Mind, 104, pp. 1-61.

Chomsky, Noam (1995b), The Minimalist Program, Cambridge, Mass.: MIT Press.

Chomsky, Noam (1995c), "Bare Phrase Structure", in: Webelhuth, Gert (ed.) (1995), Government and Binding Theory and the Minimalist Program, Cambridge: Blackwell, pp. 383- 439.

Chomsky, Noam (2000), New Horizons in the Study of Language and Mind, Cambridge: CUP.

Chomsky, Noam (2004), "Beyond Explanatory Adequacy", in: Belletti, Adriana (ed.) (2004), Structures and Beyond. The Cartography of Syntactic Structures, Oxford: OUP, pp. 104-131.

Christensen, Ken Ramshøj (2005), Interfaces: Negation - Syntax - Brain, Department of English \& The MR Research Centre, Aarhus University Hospital, Aarhus University: Ph. D.

Christensen, Ken Ramshøj (2008), "Interfaces, syntactic movement, and neural activation: A new perspective on the implementation of language in the brain", Journal of Neurolinguistics, 21, pp. 73-103.

Culicover, Peter W., Ray S. Jackendoff (2005), Simpler Syntax, Oxford: OUP.

Dietrich, Eric, Arthur B. Markman (2003), "Discrete Thoughts: Why Cognition Must Use Discrete Representations", Mind \& Language, 18, pp. 95-119.

Dretske, Fred I. (1981), Knowledge and the Flow of Information, Oxford: Blackwell. 
Dretske, Fred I. (1986), "Misrepresentation", in: Bogdan, R. (ed.) (1986), Belief: Form, Content, and Function, Oxford: Clarendon Press.

Dretske, Fred I. (1988), Exlaining Behavior, Cambridge, Mass.: MIT Press.

Dretske, Fred I. (1995), Naturalizing the Mind, Cambridge, Mass.: MIT Press.

Egan, Frances (1995), "Computation and Content", Philosophical Review, 104, pp. 181-204.

Egan, Frances (2003), "Naturalistic Inquiry", in: Antony, Louise M., Norbert Hornstein (eds.) (2003), Chomsky and his Critics, Oxford: Blackwell, pp. 89104.

Feldman, Jerome A. (2008), From Molecule to Metaphor. A Neural Theory of Language, Cambridge, Mass.: Bradford Books.

Floridi, Luciano (2005), "Semantic Conceptions of Information", in: Stanford Encyclopedia of Philosophy, Palo Alto: Stanford University.

Fodor, Jerry A. (1975), The Language of Thought, New York: Thomas Crowell.

Fodor, Jerry A. (1990), A Theory of Content and Other Essays, Cambridge, Mass.: MIT Press.

Fodor, Jerry A. (1998), Concepts: Where Cognitive Science Went Wrong, Oxford: Clarendon Press.

Gazdar, G., E. Klein, G. Pullum, I. Sag (1985), Generalized Phrase Structure Grammar, Oxford: Blackwell.

Haegeman, Liliane (1991), Introduction to Government and Binding Theory, Oxford: Blackwell.

Hauser, Marc D., Noam Chomsky, W. Tecumseh Fitch (2002), "The Faculty of Language: What Is It, Who Has It, and How Did It Evolve?", Science, 298, pp. 1569-1579.

Hawkins, John A. (2004), Efficiency and complexity in grammars: Oxford Linguistics, Oxford: OUP.

Jackendoff, Ray S., Steven Pinker (2005), "The Nature of the Language Faculty and Its Implications for Evolution of Language (Reply to Fitch, Hauser, and Chomsky)", Cognition, 97, pp. 211-225.

Lambrecht, Knud (1994), Information Structure and Sentence Form, Cambridge: CUP (= Cambridge Studies in Linguistics, Vol. 71).

Lasnik, Howard (2001), "Derivation and Representation", in: Baltin, Mark, Chris Collins (eds.) (2001), The Handbook of Contemporary Syntactic Theory, pp. 6288, Oxford: Blackwell (2003).

MacWhinney, Brian (2002), "Language Emergence", in: Burmeister, P., T. Piske, A. Rohde (eds.) (2002), An Integrated View of Language Development - Papers in Honor of Henning Wode, Trier: Wissenschaftlicher Verlag, pp. 17-42.

Marr, David (1982), Vision: A Computational Investigation into the Human Representation and Processing of Visual Information, San Francisco: W.H. Freeman. 
Millikan, Ruth Garrett (1984), Language, Thought, and Other Biological Categories, Cambridge, Mass.: MIT Press.

Newmeyer, Frederick J. (1998), Language Form and Language Function, Cambridge, Mass.: MIT-Press.

Peacocke, Christopher (1986), "Explanation in Computational Psychology: Language, Perception and Level 1.5", Mind and Language, 1, pp. 101-123.

Postal, Paul (2003), "(Virtually) Conceptually Necessary", Journal of Linguistics, 39, pp. 599-620.

Searle, John R. (1992), The Rediscovery of the Mind, Cambridge, MA: MIT-Press.

Sperber, Dan, Wilson, Deirdre (1986), Relevance: Communication and Cognition, Oxford: Blackwell.

Thrane, Torben (1992a), "The Computations of Text Comprehension", paper presented at the $3^{\text {rd }}$ Nordic Conference on Text Comprehension in Man and Machine, University of Linköping.

Thrane, Torben (1992b), "Dynamic Text Comprehension", in: Jansen, Steen (ed.) (1992), Computational Approaches to Text Understanding, pp. 173-190. Copenhagen: Museum Tusculanum.

Thrane, Torben (2004a), "Hvorfor er sproget så svært at forstå når det er så let at forstå?", Tidsskrift for Sprogforskning, 2, pp. 37-70.

Thrane, Torben (2004b), "Constituents", in: Aertsen, Henk, Mike Hannay, Rod Lyall (eds.) (2004), Words in their places: A Festschrift for J. Lachlan Mackenzie, Amsterdam: Vrije Universiteit, pp. 367-379.

Thrane, Torben (2008), "Towards an Information-Based Theory of Language", in: Birkelund, Merete, Mai-Britt Mosegaard Hansen, Coco Norén (eds.) (2008), L'énonciation dans tous ses états, Frankfurt am Main: Peter Lang, pp. 703-728.

Townsend, David J., Bever, Thomas G. (2001), Sentence Comprehension. The Integration of Habits and Rules, Cambridge, Mass.: MIT-Press.

Vargha-Khadem, Faraneh, Gadian, David G., Copp, Andrew, Mishkin, Mortimer (2005), "FOXP2 and the Neuroanatomy of Speech and Language, in: Nature Reviews Neuroscience, 6, pp. 131-138.

\section{NOTES}

1 This section draws freely and selectively on a number of Dretske's works, particularly 1988, Chapter 3, and 1995, Chapter 1, which together provide the most comprehensive general coverage of representational systems I have come across. There are, to be sure, many descriptions of concrete implementations of dedicated representational systems in the Artificial Intelligence and Cognitive Science literatures, as well as alternative general descriptions, like Millikan (1984). However, they all conform to the general requirements on such systems (except perhaps the notion of misrepresentation) that Dretske proposes, so I focus on Dretske's descriptions and taxonomies, in particular those aspects of them that have a direct bearing on the main issue here - the representational function of HLF.

2 Chomsky sometimes says, e.g. 2000: 161, that David Marr is often incorrectly attributed views that might be construed as 'externalist'. It could be because of passages like this. 
3 The external receptacles of sensory information - eyes, nose, mouth/tongue, ears at least - also carry information about themselves. But having blue, or pretty, eyes is not a necessary condition on seeing well.

4 I suppose it could be argued that 'derivation by phase' is an attempt to make syntactic theory more (purely) derivational.

5 Central among these is that the added neuronal activity empirically recorded in connection with the processing of wh-structures is due to movement, and not, for example, caused by the need to maintain the wh-element in working memory for resolution of 'filler - gap' dependencies; cf. e.g. Hawkins (2004: 169ff) for a survey of psycholinguistic explanations.

6 The three terms concern, respectively, the autonomy of syntax relative to other linguistic 'modules' (AUTOSYN), the autonomy of HLF relative to other cognitive faculties (AUTOGRAM), and whether our knowledge of the language system ('competence') is independent of our knowledge of how to use it ('performance') (AUTOKNOW). 